\title{
Pulmonary hypertension in chronic obstructive pulmonary disease and emphysema patients: prevalence, therapeutic options and pulmonary circulatory effects of lung volume reduction surgery
}

\author{
Isabelle Opitz ${ }^{1}$, Silvia Ulrich ${ }^{2}$ \\ ${ }^{1}$ Department of Thoracic Surgery, ${ }^{2}$ Department of Respiratory Diseases, University Hospital Zurich, Zurich, Switzerland \\ Correspondence to: Professor Isabelle Opitz, MD, FEBTS. Department of Thoracic Surgery, University Hospital Zurich, Raemistrasse 100, CH-8091 \\ Zurich, Switzerland. Email: isabelle.schmitt-opitz@usz.ch.
}

\begin{abstract}
The exact prevalence of pulmonary hypertension $(\mathrm{PH})$ and cor pulmonale $(\mathrm{CP})$ in chronic obstructive pulmonary disease (COPD) is unknown, and varies considerably from $20-91 \%$. Usually, mean pulmonary artery pressure (mPAP) does not exceed $30 \mathrm{mmHg}$, and $\mathrm{PH}$ is not severe. However, $\mathrm{PH}$ and $\mathrm{CP}$ are important predictors of mortality in COPD and contribute to disability in this disease. Many factors contribute to the development of $\mathrm{PH}$ in chronic lung disease, including reduction of the pulmonary vascular cross-sectional area due to parenchymal loss and accompanying hypoxia, effects of abnormal pulmonary mechanics due to hyperinflation, but also vascular remodeling processes. So far, $\mathrm{PH}$ associated with chronic lung disease cannot be treated medically. Therefore, it is indicated to treat the underlying pulmonary disease. Patients with severe $\mathrm{PH}$ should be referred to centers experienced in the management of $\mathrm{PH}$ and enrollment in clinical trials should be considered. Lung volume reduction surgery (LVRS) theoretically further increases pulmonary vascular resistance (PVR) by reducing the vascular bed when resecting lung tissue, however, this might be compensated by better pulmonary mechanics through reduction of hyperinflation, which will be discussed in the present article.
\end{abstract}

Keywords: Lung volume reduction surgery (LVRS); pulmonary hypertension (PH); emphysema; chronic obstructive pulmonary disease (COPD); cor pulmonale (CP)

Submitted Apr 26, 2018. Accepted for publication Jul 12, 2018.

doi: $10.21037 /$ jtd.2018.07.63

View this article at: http://dx.doi.org/10.21037/jtd.2018.07.63

\section{Introduction}

Pulmonary hypertension (PH) group 3, according to the 2003 World Health Organization (WHO) classification of $\mathrm{PH}$ (1), summarizes PH associated with disorders of the respiratory system. Chronic obstructive pulmonary disease (COPD), interstitial lung disease (ILD), and obstructive sleep apnea (OSA) are most frequently the underlying lung diseases in WHO group $3 \mathrm{PH}$ (2). If chronic lung disease is accompanied by $\mathrm{PH}$, functional capacity and survival will decrease, while complications will increase (2). The present article aims to give an overview of the available literature describing the outcome and potential therapeutic implications for emphysema patients with $\mathrm{PH}$, including lung volume reduction surgery (LVRS), although only limited data is available for this particular question.

\section{Epidemiology of PH in lung disease}

In contrast to idiopathic pulmonary arterial hypertension $(\mathrm{PAH})$ [mean pulmonary artery pressure $(\mathrm{mPAP})>25 \mathrm{mmHg}$, the threshold in $\mathrm{PH}$ group 3 was set at a resting mPAP $>20 \mathrm{mmHg}$ in earlier studies (3).

The exact prevalence of $\mathrm{PH}$ and cor pulmonale (CP) in COPD is unknown, and varies considerably from $20-91 \%$ 

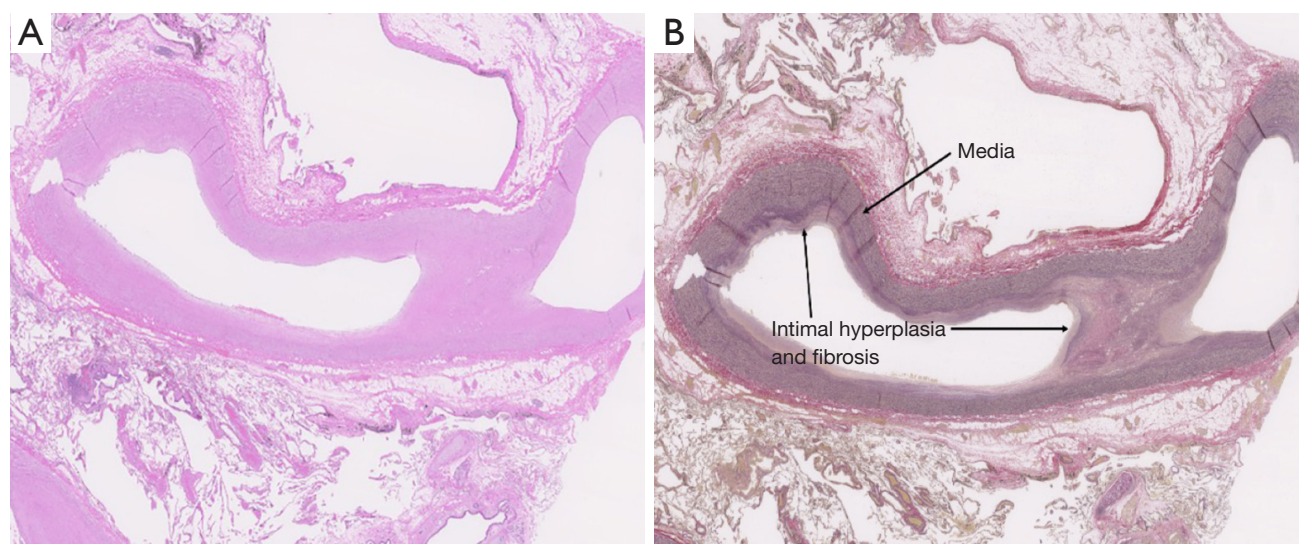

Figure 1 Vascular remodeling in an emphysema patient with $\mathrm{PH}$ (A, hematoxylin eosin staining; B, Elastica van Gieson staining), showing narrowing of the arterial lumen due to eccentric intimal hyperplasia and fibrosis. Courtesy of Dr. B. Vrugt, Institute of Pathology, University Hospital Zurich Switzerland. PH, pulmonary hypertension.

(4-12), which can be explained by variation of $\mathrm{PH}$ thresholds being used in different studies. In a large study of advanced COPD candidates for LVRS or lung transplantation, the reported prevalence of $\mathrm{PH}$ was just over $50 \%$ (7). Similar prevalence of $47.6 \% \mathrm{PH}$ of $\mathrm{mPAP} \geq 25 \mathrm{mmHg}$ is reported from the Organ Procurement and Tissue Network (OPTN) database of 4,930 COPD patients listed for transplant between 1997 and 2006 (13). In contrast to this, in the National Emphysema Treatment Trial (NETT) $\mathrm{PH}$ prevalence was as high as $91 \%$ in 120 patients where right heart catheterization (RHC) was performed (8). Several studies in patients with previous Global Initiative for Chronic Obstructive Lung Disease (GOLD) stage IV showed that only $3 \%$ to $5 \%$ of patients present with mPAP $>35$ to $40 \mathrm{mmHg}$ (14-16). The rate of $\mathrm{PH}$ progression in COPD has been reported to be normally slow with an increase in PAP between 1.5-2.8 $\mathrm{mmHg} /$ year $(17,18)$. Combined pulmonary fibrosis and emphysema (CPFE) patients develop more frequently $\mathrm{PH}$, in $30 \%$ to $50 \%$ of the cases with prognostic impact on shorter survival (19-21).

\section{Pathophysiology}

Several mechanisms may be responsible for the pathogenesis of $\mathrm{PH}$ in the setting of COPD and emphysema: reduction of the pulmonary vascular cross-sectional area due to parenchymal loss and accompanying alveolar hypoxia, hypoxemia and hypercapnia, effects of abnormal pulmonary mechanics due to air-trapping and hyperinflation, polycythemia (leading to hyperviscosity and hypervolemia), and inflammation-induced vascular remodeling related to smoking $(7,16)$. Vascular remodeling is further triggered by chronic hypoxic pulmonary vasoconstriction leading to intimal medial hypertrophy of small pulmonary arteries (22) (Figure 1).

\section{Right and left ventricular (LV) function in CP}

With rising pulmonary vascular resistance (PVR), the right ventricle (RV) slowly becomes hypertrophic and dilated. Severe emphysema is always associated with hyperinflation, and the low elastic recoil of the lungs compresses the two ventricles into each other (23), hindering the RV to dilate and increase end-diastolic volume and therefore resulting in lower cardiac output (CO) due to decreased RV preload. LV function depends on $\mathrm{RV}$ function and is therefore altered too, because changes in RV output must invariably alter $\mathrm{LV}$ preload, as the two ventricles are serially linked through the pulmonary vasculature. Furthermore, LV preload can also be directly influenced by changes in RV enddiastolic volume (RVEDV) by the mechanism of ventricular interdependence in a common pericardial pocket.

At this point, LVRS with a decrease of hyperinflation and therefore a decrease in intrathoracic pressure may help to increase cardiac function (24), which will be further discussed in the following paragraphs.

\section{Clinical relevance and effect of PH on prognosis}

In COPD an accelerated further increase of mPAP is 


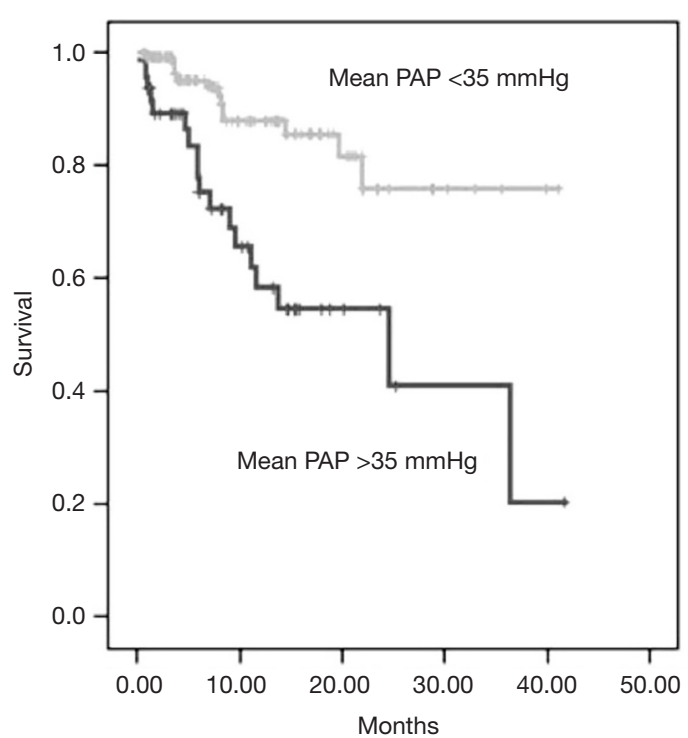

Figure 2 Effect of mPAP on survival in 176 consecutive patients with various pulmonary diseases, most of which were COPD $(n=45)$ and ILD ( $\mathrm{n}=55)$. mPAP, mean pulmonary artery pressure; COPD, chronic obstructive pulmonary disease; ILD, interstitial lung disease. From Klinger, 2016 (2).

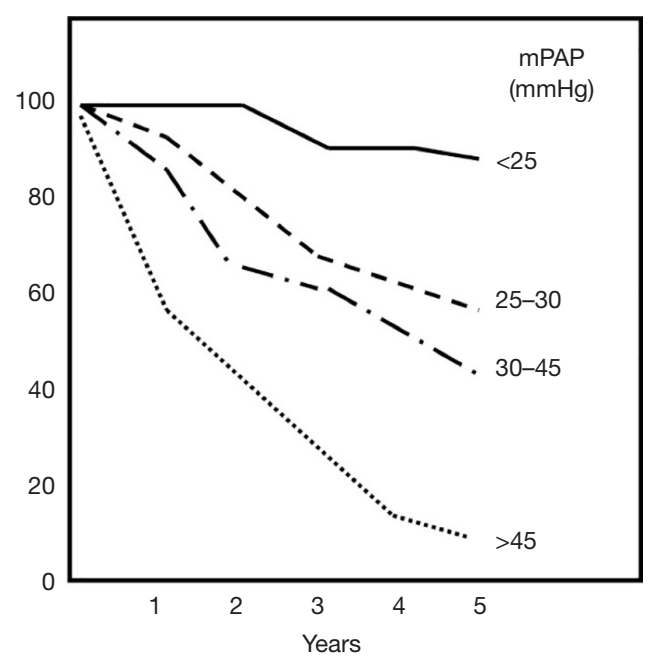

Figure 3 Effect of mPAP on survival in patients with COPD according to severity of mPAP increase. Note the marked negative effect on survival as $\mathrm{PH}$ becomes more severe (2). mPAP, mean pulmonary artery pressure; COPD, chronic obstructive pulmonary disease; PH, pulmonary hypertension. From Klinger, 2016 (2).

characteristic even under modest exercise conditions, suggesting deficits of lung vascular distension and/or vessel recruitment ability (25). In patients with severe COPD,
PAP may double to its resting value (26), this means that for those patients even daily activities such as walking or climbing stairs can lead to transient PH. Furthermore, it has been shown that PAP can rise by nocturnal desaturation in COPD patients, but its role in the pathogenesis of $\mathrm{PH}$ and CP is not clear $(27,28)$.

Patients with increased PAP also have increased morbidity and adverse events, which has for example been demonstrated (29) to result in a doubling of the hospitalization rate in patients with COPD with $\mathrm{PH}$ in comparison to those without PH. Furthermore, PAP and $\mathrm{pCO}_{2}$ were the only two factors independently predicting hospitalization. Another predictor of hospitalization due to acute COPD exacerbation seems to be larger PA diameter measured in computed tomography (CT) scan (30).

The presence of $\mathrm{PH}$ in COPD patients has also an impact on overall prognosis as it has been shown to be of a strong predictor of mortality (Figure 2). Even if only moderate; an inverse correlation between mPAP and/ or PVR values and survival has been reported $(4,15,31)$. For COPD patients $\mathrm{PH}>25 \mathrm{mmHg}$ (Figure 3), the 5 -year survival rate is relevantly decreased and it has been demonstrated that pulmonary hemodynamics have a bigger prognostic impact on survival than FEV1 or the degree of hypoxemia or hypercapnia (31). For COPD patients with severe $\mathrm{PH}>40 \mathrm{mmHg}, 5$-year survival is only about $15 \%(14,32)$.

\section{Diagnostic assessment}

The routine assessment of PAP in COPD patients is not stated in the most recent GOLD recommendation for diagnosis and initial assessment by the GOLD guidelines (33).

\section{Clinical features}

Unfortunately, the clinical features are not sensitive and specific: the classical signs of $\mathrm{PH}$ and $\mathrm{CP}$ like loud pulmonic valve closure (P2), third heart sound (S3) gallop, systolic murmur of tricuspid regurgitation are reduced due to hyperinflation (34).

\section{Brain natriuretic peptide (BNP)}

In severe cases of $\mathrm{PH}$ due to COPD or diffuse parenchymal lung diseases levels of $\mathrm{BNP}$ or the $\mathrm{N}$-terminal prohormone of BNP in plasma are elevated. In moderate PH BNP lacks sensitivity as it can also be increased due to left 

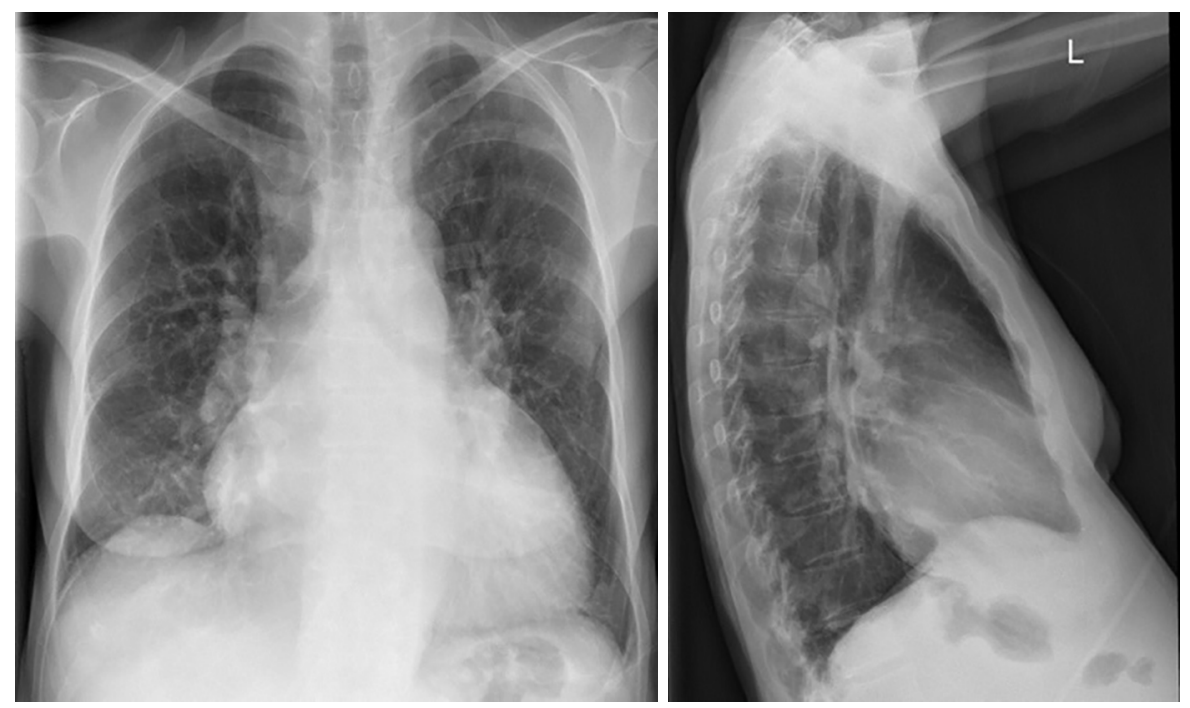

Figure 4 Chest radiography AP and lateral, courtesy of Prof. T. Frauenfelder, Institute of Diagnostic Radiology, University Hospital Zurich, Switzerland. AP, anteroposterior.

heart abnormalities (35). However, in a mixed diffuse parenchymal lung diseases population BNP levels showed a strong predictive value for mortality (36).

\section{Chest radiography}

$\mathrm{PH}$ can be diagnosed with $98 \%$ sensitivity, if the diameter of the right descending pulmonary artery (PA) is increased ( $>16 \mathrm{~mm}$, postero-anterior projection) together with an increased diameter of the left descending PA ( $>18 \mathrm{~mm}$, left lateral projection) (37) (Figure 4).

\section{ECG}

The sensitivity to detect right ventricular hypertrophy is very low. Poor prognosis is reported if $\mathrm{S} 1 \mathrm{~S} 2 \mathrm{~S} 3$ or right atrial overload pattern, i.e., $\mathrm{P}$ wave axis of $+90^{\circ}$ or more, are present (38).

\section{Echocardiography}

As non-invasive tool for the diagnosis of $\mathrm{PH}$ in COPD Doppler transthoracic echocardiography is the first diagnostic test used. In patients with lung diseases, a positive predictive value of $32 \%$ (in comparison to $68 \%$ RHC) and a negative predictive value of $93 \%$ (compared to $67 \%$ for RHC) are stated $(39,40)$. Optimal visualization of the heart for tricuspid regurgitation by Doppler is hindered by hyperinflation and therefore assessment of systolic PAP (sPAP) was achieved only in $38 \%$ of patients, as reported for 253 COPD candidates for lung transplantation (41). In cases of important hyperinflation (residual volume $>150 \%$ ), the measurement of sPAP assessment was less feasible. This depends obviously significantly on the examiner's experience. Echocardiographically estimated sPAP showed a sensitivity of $76 \%$, a specificity of $65 \%$, a negative predictive value of $93 \%$ and a positive predictive value of $32 \%$ for the diagnosis of PH (39). If sPAP assessment was impossible, the values for $\mathrm{RV}$ abnormal morphology were $84 \%, 56 \%, 96 \%$, and $22 \%$ respectively. For the exclusion of $\mathrm{PH}$ the negative predictive value is sufficient, but for the diagnosis of $\mathrm{PH} \mathrm{RHC}$ is required.

\section{CT scan}

Typical CT systemic vascular characteristics (Figure 5) are: enlargement of central pulmonary vessels, enlargement and hypertrophy of $\mathrm{RV}$, pericardial effusion.

\section{Magnetic resonance imaging (MRI)}

Contrast MRI reflects very well the RV structure and function. The thickness of the RV wall and the mean PAP show a high correlation ( $r=0.9)$ (42). One study measured PA cross-sectional area using MRI to assess if pulmonary hyperinflation correlates with PA cross-sectional area in 

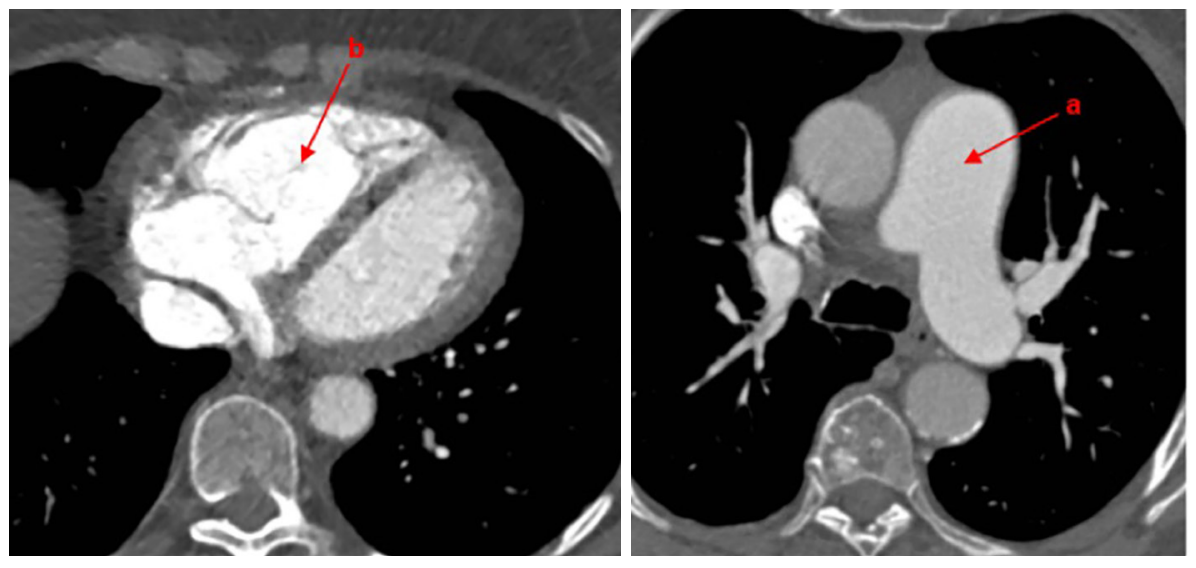

Figure 5 CT systemic vascular characteristics. a, enlargement of central pulmonary vessels; b, enlargement and hypertrophy of RV. (Courtesy Prof. T. Frauenfelder). RV, right ventricle.

COPD (43) and it has been demonstrated that increased residual volume was associated with a larger PA in COPD.

\section{RHC}

RHC is still the gold standard for precise PAP measurement. With RHC it is also possible to measure the transpulmonary gradient and CO, and to calculate PVR as well as its reversibility by drugs and oxygen. Exercise induced $\mathrm{PH}$ can also be investigated. Severe $\mathrm{PH}$ (mPAP $>40 \mathrm{mmHg}$ ) is rarely seen in COPD and in these cases an additional explanation for $\mathrm{PH}$ should be investigated, e.g., left heart disease, chronic thromboembolic disease or idiopathic.

\section{Cardiopulmonary exercise testing (CPET)}

Exercise testing is an excellent tool to differentiate between an exhausted breathing reserve caused by airflow limitation and an exhausted circulatory reserve caused by PH (44).

\section{Treatment}

Even though PAP has a strong negative impact on survival in most lung diseases, findings from a limited number of studies suggest that successful treatment of $\mathrm{PH}$ does not necessarily improve patients' outcome. Before starting a $\mathrm{PH}$ treatment for patients with chronic lung disease, it has to be considered, whether improving pulmonary hemodynamics in chronic lung disease has an impact on patients outcome, because in most of these patients symptoms are rather caused by limitations in ventilation than by $\mathrm{CO}$, unlike those with idiopathic PAH (2). Management of the underlying lung disease is the primary goal of treatment, as there is currently no medication proven to efficiently treat $\mathrm{PH}$ associated with chronic lung disease. In cases of severe $\mathrm{PH}$, patients should be referred to experienced PAH centres and enrollment in clinical trials should be considered.

Over the past 2 decades, a large number of drugs have been approved for WHO group $1 \mathrm{PAH}$, leading to the temptation to also use these medications in the treatment of $\mathrm{PH}$ associated with chronic lung disease (2).

\section{Therapy of CP}

Treatments include $\alpha 1$-antagonists, $\beta 2$-agonists, angiotensin converting enzyme inhibitors, calcium channel blockers, nitrates, and theophylline (45). The majority of these drugs influence $\mathrm{PH}$ only modestly, as on the one hand they increase CO and reduce PVR, but on the other hand also lead to systemic hypotension and deterioration of ventilation-perfusion mismatch. Whether these alternative treatments lead to a benefit of survival has not yet been shown for any of them (45).

\section{Oxygen}

In the 1970s, the efficacy of supplemental oxygen to reduce PAP in COPD was first studied. The effects of long-term oxygen therapy (LTO2) on pulmonary hemodynamics, patient function, and survival was assessed in two large multicenter studies. Although it has been demonstrated that mortality was relevantly influenced by the oxygen therapy, 
increased survival was not correlated with changes in pulmonary hemodynamics (17). This was further confirmed by the Nocturnal Oxygen Therapy Trial [randomized to overnight (average $12 \mathrm{~h} / \mathrm{d}$ ) or continuous (average $17.7 \mathrm{~h} / \mathrm{d}$ ) LTO2 (46)] which showed nearly double mortalities in nocturnal vs the continuous oxygen therapy group, but showed no differences in mPAP and PVR between the group of continuous oxygen compared to the group who used oxygen only at night. However, oxygen is still vital in the treatment for $\mathrm{PH}$ in COPD patients.

\section{Pulmonary vasodilators}

The use of vasodilatators is complicated by the negative effect on oxygenation by inhibiting the ventilation perfusion mechanism. However, small series in well selected patients showed a benefit $(47,48)$.

Nitrite oxide was tested in one long-term study in 40 patients who were additionally under LTO2 (49). Although significant improvement of PAP, PVR and CO was demonstrated, technological and toxicological problems connected to long-term use of inhaled NO still need to be resolved.

Inhaled prostanoids can acutely lead to reduction of $\mathrm{mPAP}$ and PVR without negative impact on gas exchange in PH-COPD (50), but long-term effects have not been studied so far.

Controversial data exist about the effect of endothelin receptor antagonists in PH-COPD. Bosentan was assessed in a small randomized controlled trial in COPD patients with no or only mild $\mathrm{PH}$ assessed by echocardiography. While gas exchange was even deteriorated, peak oxygen uptake, exercise capacity, and quality of life were also not improved (51). Valerio et al. reported, that Bosentan treatment can improve exercise capacity in $\mathrm{PH}-\mathrm{COPD}$ patients (52).

Short-term application of phosphodiesterase inhibitor sildenafil was tested in PH-COPD and better hemodynamics, but at the same time worsened gas exchange was documented (53). This is further confirmed by a small randomized controlled trial in patients with severe $\mathrm{PH}-$ COPD upon long-term use of sildenafil where a reduction in PAP and an increase in 6-minute walking distance, was observed (54). Taken together, there is no evidence that patients with COPD without severe $\mathrm{PH}$ have a long-term benefit from sildenafil treatment.

PH-COPD patients on riociguat medication showed improved pulmonary hemodynamics in the absence of major gas exchange deterioration (55). Further studies are needed to explore this indication for riociguat.

\section{LVRS}

LVRS significantly improves lung function, gas exchange, exercise capacity, quality of life and even survival for emphysema patients when compared to medical treatment (56,57). Experienced centers with careful patient selection, can reach a 90 days-postoperative mortality rate nearing zero $(58,59)$. PH is still an exclusion criteria for LVRS for emphysema patients (60). This was based on the idea that resection of lung tissue and therefore reduction of the vascular bed would favor PH. However, PVR and therefore $\mathrm{PH}$ should improve due to the by LVRS achieved reduction of hyperinflation and air-trapping. It is not clear though if the change of $\mathrm{PH}$ after LVRS is caused by reduction in hyperinflation only or rather by improved arterial oxygen tension. In two case series with endoscopic lung volume reduction with valves, it has been shown that clinical and hemodynamic parameters ( $\mathrm{PH}$ and $\mathrm{RV}$ function) improved without increasing morbidity and mortality of the procedure $(61,62)$. Limited data on the influence of LVRS on cardiac function and hemodynamics exist and are controversial.

Haniuda et al. (63) compared the results of seven patients 6 months before and after LVRS at rest and during exercise with the results of eight pulmonary lobectomy patients: after lobectomy, sPAP was strongly increased during exercise, while sPAP at rest or during exercise was not influenced by LVRS. In none of the groups cardiac index was influenced, neither at rest nor during exercise. In the LVRS group the elevation of wedge pressure during exercise even ameliorated $(\mathrm{P}<0.01)$. This was further confirmed by Criner et al. (64), in a cardiovascular subanalysis of three out of seventeen centers for the NETT: after LVRS PAP did not increase in comparison with medical therapy. The same results are reported from Kubo and colleagues (65): PAP at rest or during exercise is unaffected six months after bilateral LVRS. A slight, but non-significant decrease in exercising mPAP was shown in a small study including 9 LVRS patients; mPAP at rest was unaffected (66). In contrast to this, another small study (67) reported an increase in mean PAP in 9 subjects from 26.5 to $31.8 \mathrm{mmHg} 3$ months after surgery, and in 3 patients $\mathrm{PAP}$ even rose to $60 \mathrm{mmHg}$ or greater. In another prospective, longitudinal study, nine emphysema patients with an average age of $64.4 \mathrm{yr}$. treated with LVRS experienced a significant rise of FEV1 from 0.64 preoperatively to $0.99 \mathrm{~L}$ postoperatively. In the same study 
Table 1 Lung function of patients with sPAP < or $>35 \mathrm{mmHg}$ pre- and post LVRS

\begin{tabular}{|c|c|c|c|c|}
\hline Variables & Median preoperative (IQR) & Median postoperative (IQR) & $\Delta$ from baseline (\%) & $P$ value \\
\hline FEV1 (\% predicted) & 24 [20-30] & 29 [23-33] & 21 & 0.020 \\
\hline FEV1 (mL) & 700 [515-948] & 800 [590-990] & 14 & 0.003 \\
\hline TLC (\% predicted) & 122 [112-148] & 119 [107-137] & -2 & 0.001 \\
\hline RV (\% predicted) & 231 [180-275] & 208 [165-246] & -10 & 0.001 \\
\hline $\mathrm{RV}(\mathrm{mL})$ & $4,785[4,235-6,443]$ & $4,415[3,552-5,570]$ & -8 & 0.001 \\
\hline RV/TLC (\%) & 67 [62-73] & 62 [55-66] & -2 & 0.001 \\
\hline DLCO (\% predicted) & $31[22-37]$ & 25 [16-39] & -7 & 0.394 \\
\hline FEV1 (mL) & 675 [635-785] & $805[760-1,020]$ & 19 & 0.007 \\
\hline TLC (\% predicted) & 129 [126-163] & 125 [106-143] & -3 & 0.086 \\
\hline TLC (mL) & $7,380[6,620-9,667]$ & $6,435[6,115-7,457]$ & -13 & 0.047 \\
\hline RV (\% predicted) & 266 [224-310] & 227 [187-244] & -15 & 0.012 \\
\hline $\mathrm{RV}(\mathrm{mL})$ & $5,710[4,885-7,915]$ & $4,605[3,820-5,280]$ & -19 & 0.018 \\
\hline RV/TLC (\%) & 76 [73-79] & $66[59-71]$ & -13 & 0.013 \\
\hline DLCO (\% predicted) & 32 [21-38] & 30 [15-41] & -6 & 0.686 \\
\hline
\end{tabular}

DLCO, carbon monoxide diffusion capacity; sPAP, systolic pulmonary artery pressure; FEV1, forced expiratory volume in 1s; IQR, interquartile range; RV, residual volume; TLC, total lung capacity.

PAP rose to $47.9 \pm 12.4 \mathrm{mmHg}$ after surgery, but the change was not statistically significant (67).

In our own cohort, we retrospectively assessed the effect on PH in 119 LVRS patients (68), and we could demonstrate even significant improvement of $\mathrm{PH}$ in patients with heterogeneous emphysema. In patients with $\mathrm{PH}$, median sPAP decreased from $41 \mathrm{mmHg}$ [interquartile range (IQR) 39-47 to $37 \mathrm{mmHg}$ (IQR) 36-38, $\mathrm{P}=0.04$ ]. FEV1 improved in these patients three months after surgery from median $27 \%$ predicted (IQR 23-34) to 33\% (IQR $28-40, \mathrm{P}=0.007$ ) (Table 1). These inverse changes of PAP levels with FEV1 in a subset of patients treated with LVRS have also been documented by other groups $(7,8)$.

In terms on the effect of LVRS on RV function, the results are equally controversial: whereas some groups showed $(65,69)$ that cardiac index, both at rest and during exercise, increased 6 months after LVRS, Sciurba et al. (23) reported that LVRS significantly increased RV systolic function (Figure 6); other groups could not confirm these findings $(63,66,67)$. The improvement in RV function may be explained by several facts: due to the reduction of hyperinflation, a decrease of the intrathoracic pressure might cause an improved RV filling-and therefore improved RV preload-reflected in increased RVEDVs after LVRS as described by Mineo et al. (69). Another explanation is that throughout the reduction of hyperinflation, pressure on the vessels is decreased or-by improvement of elastic recoilinduced tethering of extra-alveolar vessels, a reduction of PVR by capillary recruitment is obtained by LVRS $(6,70)$. This holds particularly true during exercise, as these large intrathoracic pressure swings are a well-known mechanism for emphysematous patients to overcome the loss of lung elastic recoil. In the study by Oswald-Mammosser, a significant decrease of the respiratory swings of the pulmonary diastolic pressure at rest and during exercise was observed after surgery, alongside with a good correlation between the change in mean PAP after LVRS at rest, as well as during exercise, and the change in the resting PA 


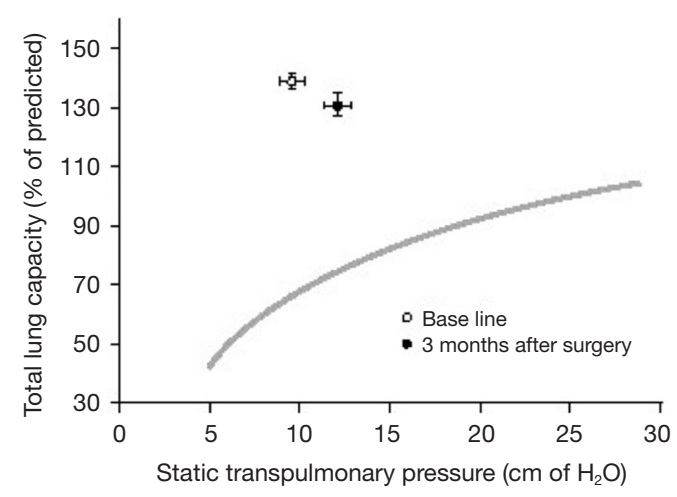

Figure 6 Mean $\left({ }_{ \pm} \mathrm{SE}\right)$ lung volume as a function of mean $\left({ }_{ \pm} \mathrm{SE}\right)$ transpulmonary pressure before (open circle) and after (solid Circle) lung-reduction surgery in 20 patients with diffuse emphysema. Note the shift to the right and downward in maximal elastic-recoil pressure and total lung capacity. Lung volume is represented as a percentage of the )total lung capacity. The curve represents the mean response in normal subjects (22). SE, standard error.

diastolic pressure $(\mathrm{r}=0.73, \mathrm{P}<0.03$ and $\mathrm{r}=0.80, \mathrm{P}<0.02$, respectively) (66). This is further supported by other studies (71-73), showing that diffusion capacity even increased after LVRS. This suggests that the alveolo-capillary gas exchange surface is not negatively influenced; maybe because damage to the vascular bed was only minimal as a result of a welltargeted resection zone, or possibly that more capillaries are recruited after LVRS. Several studies demonstrated that LVRS did not significantly change $\mathrm{PaO}_{2}$ or $\mathrm{PaCO}_{2}$ at rest or during exercise (74).

In a prospective, open, controlled study of LVRS patients with severe emphysema (10 patients) compared to cancer lobectomy serving as control subjects (10 patients), the effect on $\mathrm{LV}$ function was assessed by transesophageal echocardiography, and hemodynamics were assessed by RHC before and after surgery. Preoperative LV function was impaired in LVRS patients [lower CI, stroke volume index (SVI)] in comparison to patients undergoing lobectomy for lung carcinoma, and improved postoperatively after LVRS as reflected by an increase in LV end-diastolic morphology, and therefore improved LV function. The pressure reduced LV function in the LVRS groups might be explained again by dynamic hyperinflation decreasing the intrathoracic blood volume, which further generates an intrinsic positive end-expiratory pressure (PEEP) (75-78). Indeed, it has been demonstrated that patients with severe emphysema have intrinsic PEEP levels between $5-7.5 \mathrm{cmH}_{2} \mathrm{O}(76,77)$, which has been further correlated to impairment of $\mathrm{RV}$ and $\mathrm{LV}$ end-diastolic dimensions in assessments of patients and volunteers (79-85). Taken together, these results strongly support the idea that LVRS in patients with severe emphysema might increase both $\mathrm{RV}$ and $\mathrm{LV}$ function after surgery.

\section{Summary and conclusions}

* Prevalence of PH and CP in COPD patients ranges from $20-91 \%$, but is mostly only moderate with mPAP usually not exceeding $30 \mathrm{mmHg}$.

* Morbidity and mortality in chronic lung disease is strongly affected by the presence of even moderate $\mathrm{PH}$.

* PH in chronic lung disease is caused by multiple factors including reduction of the pulmonary vascular crosssectional area, hypoxia, effects of abnormal pulmonary mechanics due to hyperinflation, but also vascular remodeling processes.

* Management of the underlying lung disease is the primary goal of treatment, as there is currently no medication proven to efficiently treat $\mathrm{PH}$ associated with chronic lung disease.

* In cases of severe PH, patients should be referred to experienced $\mathrm{PAH}$ centres and enrollment in clinical trials should be considered.

- Based on the present literature lacking prospective or randomized data, LVRS has in most series no adverse effect on pulmonary hemodynamics. The decrease of PVR resulting from better pulmonary mechanics with reduction of hyperinflation, and improved elastic recoil might compensate for the anatomic reduction of the vascular bed. If resection areas are well targeted, this effect may be even positive for pulmonary hemodynamics, which needs to be demonstrated in further prospective trials.

\section{Acknowledgements}

I thank Dr. Chloe Spichiger and Dr. Martina Friess for supporting me in the edition and formatting process. I further thank Professor Thomas Frauenfelder and Dr. med. Bart Vrugt for imaging and histopathological slides.

\section{Footnote}

Conflicts of Interest: The authors have no conflict of interest to declare. 


\section{References}

1. Rubin LJ, American College of Chest Physicians. Diagnosis and management of pulmonary arterial hypertension: ACCP evidence-based clinical practice guidelines. Chest 2004;126:7S-10S.

2. Klinger JR. Group III Pulmonary Hypertension: Pulmonary Hypertension Associated with Lung Disease: Epidemiology, Pathophysiology, and Treatments. Cardiol Clin 2016;34:413-33.

3. Galie N, Hoeper MM, Humbert M, et al. Guidelines for the diagnosis and treatment of pulmonary hypertension: the Task Force for the Diagnosis and Treatment of Pulmonary Hypertension of the European Society of Cardiology (ESC) and the European Respiratory Society (ERS), endorsed by the International Society of Heart and Lung Transplantation (ISHLT). Eur Heart J 2009;30:2493-537.

4. Burrows B, Kettel LJ, Niden AH, et al. Patterns of cardiovascular dysfunction in chronic obstructive lung disease. N Engl J Med 1972;286:912-8.

5. Weitzenblum E, Sautegeau A, Ehrhart M, et al. Longterm course of pulmonary arterial pressure in chronic obstructive pulmonary disease. Am Rev Respir Dis 1984;130:993-8.

6. Oswald-Mammosser M, Apprill M, Bachez P, et al. Pulmonary hemodynamics in chronic obstructive pulmonary disease of the emphysematous type. Respiration 1991;58:304-10.

7. Thabut G, Dauriat G, Stern JB, et al. Pulmonary hemodynamics in advanced COPD candidates for lung volume reduction surgery or lung transplantation. Chest 2005;127:1531-6.

8. Scharf SM, Iqbal M, Keller C, et al. Hemodynamic characterization of patients with severe emphysema. Am J Respir Crit Care Med 2002;166:314-22.

9. Chatila WM, Thomashow BM, Minai OA, et al. Comorbidities in chronic obstructive pulmonary disease. Proc Am Thorac Soc 2008;5:549-55.

10. Falk JA, Kadiev S, Criner GJ, et al. Cardiac disease in chronic obstructive pulmonary disease. Proc Am Thorac Soc 2008;5:543-8.

11. Chaouat A, Naeije R, Weitzenblum E. Pulmonary hypertension in COPD. Eur Respir J 2008;32:1371-85.

12. Ulrich S, Hersberger M, Fischler M, et al. Genetic polymorphisms of the serotonin transporter, but not the 2a receptor or nitric oxide synthetase, are associated with pulmonary hypertension in chronic obstructive pulmonary disease. Respiration 2010;79:288-95.

13. Cuttica MJ, Kalhan R, Shlobin OA, et al. Categorization and impact of pulmonary hypertension in patients with advanced COPD. Respir Med 2010;104:1877-82.

14. Chaouat A, Bugnet AS, Kadaoui N, et al. Severe pulmonary hypertension and chronic obstructive pulmonary disease. Am J Respir Crit Care Med 2005;172:189-94.

15. Andersen KH, Iversen M, Kjaergaard J, et al. Prevalence, predictors, and survival in pulmonary hypertension related to end-stage chronic obstructive pulmonary disease. J Heart Lung Transplant 2012;31:373-80.

16. Seeger W, Adir Y, Barbera JA, et al. Pulmonary hypertension in chronic lung diseases. J Am Coll Cardiol 2013;62:D109-16.

17. Long term domiciliary oxygen therapy in chronic hypoxic cor pulmonale complicating chronic bronchitis and emphysema. Report of the Medical Research Council Working Party. Lancet 1981;1:681-6.

18. Weitzenblum E, Sautegeau A, Ehrhart M, et al. Long-term oxygen therapy can reverse the progression of pulmonary hypertension in patients with chronic obstructive pulmonary disease. Am Rev Respir Dis 1985;131:493-8.

19. Cottin V, Le Pavec J, Prevot G, et al. Pulmonary hypertension in patients with combined pulmonary fibrosis and emphysema syndrome. Eur Respir J 2010;35:105-11.

20. Cottin V, Nunes H, Brillet PY, et al. Combined pulmonary fibrosis and emphysema: a distinct underrecognised entity. Eur Respir J 2005;26:586-93.

21. Mejia M, Carrillo G, Rojas-Serrano J, et al. Idiopathic pulmonary fibrosis and emphysema: decreased survival associated with severe pulmonary arterial hypertension. Chest 2009;136:10-5.

22. Wilkinson M, Langhorne CA, Heath D, et al. A pathophysiological study of 10 cases of hypoxic cor pulmonale. Q J Med 1988;66:65-85.

23. Sciurba FC, Rogers RM, Keenan RJ, et al. Improvement in pulmonary function and elastic recoil after lungreduction surgery for diffuse emphysema. $\mathrm{N}$ Engl J Med 1996;334:1095-9.

24. Jorgensen K, Houltz E, Westfelt U, et al. Effects of lung volume reduction surgery on left ventricular diastolic filling and dimensions in patients with severe emphysema. Chest 2003;124:1863-70.

25. Wrobel JP, Thompson BR, Williams TJ. Mechanisms of pulmonary hypertension in chronic obstructive pulmonary disease: a pathophysiologic review. J Heart Lung Transplant 2012;31:557-64.

26. Weitzenblum E. Chronic cor pulmonale. Heart 
2003;89:225-30.

27. Fletcher EC, Donner CF, Midgren B, et al. Survival in COPD patients with a daytime $\mathrm{PaO} 2$ greater than $60 \mathrm{~mm} \mathrm{Hg}$ with and without nocturnal oxyhemoglobin desaturation. Chest 1992;101:649-55.

28. Chaouat A, Weitzenblum E, Kessler R, et al. Outcome of COPD patients with mild daytime hypoxaemia with or without sleep-related oxygen desaturation. Eur Respir J 2001;17:848-55.

29. Kessler R, Faller M, Fourgaut G, et al. Predictive factors of hospitalization for acute exacerbation in a series of 64 patients with chronic obstructive pulmonary disease. Am J Respir Crit Care Med 1999;159:158-64.

30. Wells JM, Washko GR, Han MK, et al. Pulmonary arterial enlargement and acute exacerbations of COPD. N Engl J Med 2012;367:913-21.

31. Oswald-Mammosser M, Weitzenblum E, Quoix E, et al. Prognostic factors in COPD patients receiving long-term oxygen therapy. Importance of pulmonary artery pressure. Chest 1995;107:1193-8.

32. Mueller-Mottet S, Stricker H, Domenighetti G, et al. Long-term data from the Swiss pulmonary hypertension registry. Respiration 2015;89:127-40.

33. Global Initiative for Chronic Obstructive Lung Disease. Global Strategy for the Diagnosis, Management, and Prevention of Chronic Obstructive Pulmonary Disease. 2018 Report.

34. MacNee W. Pathophysiology of cor pulmonale in chronic obstructive pulmonary disease. Part One. Am J Respir Crit Care Med 1994;150:833-52.

35. Leuchte HH, Baumgartner RA, Nounou ME, et al. Brain natriuretic peptide is a prognostic parameter in chronic lung disease. Am J Respir Crit Care Med 2006;173:744-50.

36. Corte TJ, Wort SJ, Gatzoulis MA, et al. Elevated brain natriuretic peptide predicts mortality in interstitial lung disease. Eur Respir J 2010;36:819-25.

37. Matthay RA, Schwarz MI, Ellis JH, Jr., et al. Pulmonary artery hypertension in chronic obstructive pulmonary disease: determination by chest radiography. Invest Radiol 1981;16:95-100.

38. Incalzi RA, Fuso L, De Rosa M, et al. Electrocardiographic signs of chronic cor pulmonale: A negative prognostic finding in chronic obstructive pulmonary disease. Circulation 1999;99:1600-5.

39. Arcasoy SM, Christie JD, Ferrari VA, et al. Echocardiographic assessment of pulmonary hypertension in patients with advanced lung disease. Am J Respir Crit Care Med 2003;167:735-40.
40. Fisher MR, Criner GJ, Fishman AP, et al. Estimating pulmonary artery pressures by echocardiography in patients with emphysema. Eur Respir J 2007;30:914-21.

41. Shujaat A, Minkin R, Eden E. Pulmonary hypertension and chronic cor pulmonale in COPD. Int J Chron Obstruct Pulmon Dis 2007;2:273-82.

42. Saito H, Dambara T, Aiba M, et al. Evaluation of cor pulmonale on a modified short-axis section of the heart by magnetic resonance imaging. Am Rev Respir Dis 1992;146:1576-81.

43. Poor HD, Kawut SM, Liu CY, et al. Pulmonary hyperinflation due to gas trapping and pulmonary artery size: The MESA COPD Study. PLoS One 2017; 12:e0176812.

44. Boerrigter BG, Bogaard HJ, Trip P, et al. Ventilatory and cardiocirculatory exercise profiles in COPD: the role of pulmonary hypertension. Chest 2012;142:1166-74.

45. MacNee $W$. An integrated approach to the treatment of pulmonary hypertension due to hypoxic lung disease. In: Peacock A, Rubin LJ, editors. Pulmonary Circulation: diseases and their treatment. second edition ed. London: Arnold; 2004:398-409.

46. Continuous or nocturnal oxygen therapy in hypoxemic chronic obstructive lung disease: a clinical trial. Nocturnal Oxygen Therapy Trial Group. Ann Intern Med 1980;93:391-8.

47. Fossati L, Muller-Mottet S, Hasler E, et al. Longterm effect of vasodilator therapy in pulmonary hypertension due to COPD: a retrospective analysis. Lung 2014;192:987-95.

48. Lange TJ, Baron M, Seiler I, et al. Outcome of patients with severe $\mathrm{PH}$ due to lung disease with and without targeted therapy. Cardiovasc Ther 2014;32:202-8.

49. Vonbank K, Ziesche R, Higenbottam TW, et al. Controlled prospective randomised trial on the effects on pulmonary haemodynamics of the ambulatory long term use of nitric oxide and oxygen in patients with severe COPD. Thorax 2003;58:289-93.

50. Boeck L, Tamm M, Grendelmeier P, et al. Acute effects of aerosolized iloprost in COPD related pulmonary hypertension - a randomized controlled crossover trial. PLoS One 2012;7:e52248.

51. Stolz D, Rasch H, Linka A, et al. A randomised, controlled trial of bosentan in severe COPD. Eur Respir J 2008;32:619-28.

52. Valerio G, Bracciale P, Grazia D'Agostino A. Effect of bosentan upon pulmonary hypertension in chronic obstructive pulmonary disease. Ther Adv Respir Dis 
2009;3:15-21.

53. Blanco I, Gimeno E, Munoz PA, et al. Hemodynamic and gas exchange effects of sildenafil in patients with chronic obstructive pulmonary disease and pulmonary hypertension. Am J Respir Crit Care Med 2010;181:270-8.

54. Rao RS, Singh S, Sharma BB, et al. Sildenafil improves six-minute walk distance in chronic obstructive pulmonary disease: a randomised, double-blind, placebo-controlled trial. Indian J Chest Dis Allied Sci 2011;53:81-5.

55. Ghofrani HA, Staehler G, Grunig E, et al. Acute effects of riociguat in borderline or manifest pulmonary hypertension associated with chronic obstructive pulmonary disease. Pulm Circ 2015;5:296-304.

56. Huang W, Wang WR, Deng B, et al. Several clinical interests regarding lung volume reduction surgery for severe emphysema: meta-analysis and systematic review of randomized controlled trials. J Cardiothorac Surg 2011;6:148.

57. Bloch KE, Russi EW, Weder W. Patient selection for lung volume reduction surgery: is outcome predictable? Semin Thorac Cardiovasc Surg 2002;14:371-80.

58. Ginsburg ME, Thomashow BM, Bulman WA, et al. The safety, efficacy, and durability of lung-volume reduction surgery: A 10-year experience. J Thorac Cardiovasc Surg 2016;151:717-24.e1.

59. Caviezel C, Franzen D, Inci I, et al. [Lung Volume Reduction Surgery - State of the Art 2016]. Zentralbl Chir 2016;141 Suppl 1:S26-34.

60. Mentzer SJ. Optimizing the selection of surgical candidates for lung volume reduction surgery. Semin Thorac Cardiovasc Surg 2007;19:151-6.

61. Eberhardt R, Gerovasili V, Kontogianni K, et al. Endoscopic lung volume reduction with endobronchial valves in patients with severe emphysema and established pulmonary hypertension. Respiration 2015;89:41-8.

62. Pizarro C, Schueler R, Hammerstingl C, et al. Impact of endoscopic lung volume reduction on right ventricular myocardial function. PLoS One 2015;10:e0121377.

63. Haniuda M, Kubo K, Fujimoto K, et al. Different effects of lung volume reduction surgery and lobectomy on pulmonary circulation. Ann Surg 2000;231:119-25.

64. Criner GJ, Scharf SM, Falk JA, et al. Effect of lung volume reduction surgery on resting pulmonary hemodynamics in severe emphysema. Am J Respir Crit Care Med 2007;176:253-60.

65. Kubo K, Koizumi T, Fujimoto K, et al. Effects of lung volume reduction surgery on exercise pulmonary hemodynamics in severe emphysema. Chest
1998;114:1575-82.

66. Oswald-Mammosser M, Kessler R, Massard G, et al. Effect of lung volume reduction surgery on gas exchange and pulmonary hemodynamics at rest and during exercise. Am J Respir Crit Care Med 1998;158:1020-5.

67. Weg IL, Rossoff L, McKeon K, et al. Development of pulmonary hypertension after lung volume reduction surgery. Am J Respir Crit Care Med 1999;159:552-6.

68. Caviezel C, Aruldas C, Franzen D, et al. Lung volume reduction surgery in selected patients with emphysema and pulmonary hypertension. Eur J Cardiothorac Surg 2018.

69. Mineo TC, Pompeo E, Rogliani P, et al. Effect of lung volume reduction surgery for severe emphysema on right ventricular function. Am J Respir Crit Care Med 2002;165:489-94.

70. Lockhart A, Tzareva M, Nader F, et al. Elevated pulmonary artery wedge pressure at rest and during exercise in chronic bronchitis: fact or fancy. Clin Sci 1969;37:503-17.

71. Gelb AF, Zamel N, McKenna RJ, Jr., et al. Mechanism of short-term improvement in lung function after emphysema resection. Am J Respir Crit Care Med 1996;154:945-51.

72. Russi EW, Weder W. News on lung volume reduction surgery. Swiss Med Wkly 2002;132:557-61.

73. Caviezel C, Schaffter N, Schneiter D, et al. Outcome After Lung Volume Reduction Surgery in Patients With Severely Impaired Diffusion Capacity. Ann Thorac Surg 2018;105:379-85.

74. Miller JI, Jr., Lee RB, Mansour KA. Lung volume reduction surgery: lessons learned. Ann Thorac Surg 1996;61:1464-8; discussion 8-9.

75. Marchand E, Gayan-Ramirez G, De Leyn P, et al. Physiological basis of improvement after lung volume reduction surgery for severe emphysema: where are we? Eur Respir J 1999;13:686-96.

76. Tschernko EM, Gruber EM, Jaksch P, et al. Ventilatory mechanics and gas exchange during exercise before and after lung volume reduction surgery. Am J Respir Crit Care Med 1998;158:1424-31.

77. Tschernko EM, Kritzinger M, Gruber EM, et al. Lung volume reduction surgery: preoperative functional predictors for postoperative outcome. Anesth Analg 1999;88:28-33.

78. Tschernko EM, Wisser W, Wanke T, et al. Changes in ventilatory mechanics and diaphragmatic function after lung volume reduction surgery in patients with COPD. Thorax 1997;52:545-50.

79. Brienza N, Dambrosio M, Cinnella G, et al. Effects of 
PEEP on intrathoracic and extrathoracic blood volumes evaluated with the COLD system in patients with acute respiratory failure. Preliminary study. Minerva Anestesiol 1996;62:235-42.

80. Peters J, Hecker B, Neuser D, et al. Regional blood volume distribution during positive and negative airway pressure breathing in supine humans. J Appl Physiol (1985) 1993;75:1740-7.

81. Huemer G, Kolev N, Kurz A, et al. Influence of positive end-expiratory pressure on right and left ventricular performance assessed by Doppler two-dimensional echocardiography. Chest 1994;106:67-73.

82. Yamada T, Takeda J, Satoh M, et al. Effect of positive end-expiratory pressure on left and right ventricular diastolic filling assessed by transoesophageal Doppler

Cite this article as: Opitz I, Ulrich S. Pulmonary hypertension in chronic obstructive pulmonary disease and emphysema patients: prevalence, therapeutic options and pulmonary circulatory effects of lung volume reduction surgery. J Thorac Dis 2018;10(Suppl 23):S2763-S2774. doi: 10.21037/ jtd.2018.07.63 echocardiography. Anaesth Intensive Care 1999;27:341-5.

83. Koolen JJ, Visser CA, Wever E, et al. Transesophageal two-dimensional echocardiographic evaluation of biventricular dimension and function during positive endexpiratory pressure ventilation after coronary artery bypass grafting. Am J Cardiol 1987;59:1047-51.

84. Mitaka C, Nagura T, Sakanishi N, et al. Two-dimensional echocardiographic evaluation of inferior vena cava, right ventricle, and left ventricle during positive-pressure ventilation with varying levels of positive end-expiratory pressure. Crit Care Med 1989;17:205-10.

85. Terai C, Uenishi M, Sugimoto H, et al. Transesophageal echocardiographic dimensional analysis of four cardiac chambers during positive end-expiratory pressure. Anesthesiology 1985;63:640-6. 